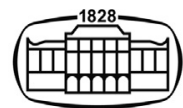

AKADÉMIAI KIADÓ

Journal of Psychedelic Studies

4 (2020) 2, 93-103

DOI:

$10.1556 / 2054.2020 .00117$

(c) 2020 The Author(s)

ORIGINAL ARTICLE

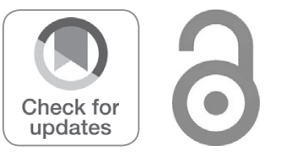

\title{
The Novelty of Ayahuasca Scale and the prediction of intentions to use
}

\author{
BRIANNA R. ALTMAN*๑, M. N. MIAN and M. EARLEYWINE
}

Department of Psychology, University at Albany, State University of New York, Albany, NY, USA

Received: September 22, 2019 - Accepted: December 1, 2019

Published online: March 09, 2020

\begin{abstract}
Objective: Given the growing popularity of ayahuasca and other hallucinogens, we sought to identify related expectancies and their role in why people might use this psychoactive brew rather than classic hallucinogens like LSD or psilocybin. Method: Experienced users $(\mathrm{N}=139)$ completed an online survey about their use of hallucinogens (including ayahuasca), how their ayahuasca experiences differed from those with other hallucinogens, as well as their intentions to use hallucinogens (including ayahuasca) in the future. Results: Participants expected ayahuasca effects to differ meaningfully from the effects of other hallucinogens in multiple domains. Expected differences involved positive connections to nature (and other people), dramatic (or terrifying) thoughts, high variability of effects, and physical reactions. Intentions to use ayahuasca in the future increased as expectancies for positive connections increased, but decreased as physical reactions increased. One version of the full Novelty of Ayahuasca scale significantly covaried with the likelihood of using ayahuasca over other hallucinogens in the future, while another version did not. This result calls for further work examining how users perceive certain ayahuasca-induced effects. Conclusions: These findings reveal that expectancies for ayahuasca differ from those for other hallucinogens, and impact an individual's willingness to try the substance again. Understanding these differences might help those who are interested in the therapeutic potential of hallucinogens decide among those available. Future studies might examine how these expectancies predict intentions to use ayahuasca (and other hallucinogens) longitudinally. Comparable approaches could also identify unique expectancies for other hallucinogens to see if those predict a preference for one over others.
\end{abstract}

\section{KEYWORDS}

ayahuasca, hallucinogens, hallucinogen expectancies

\section{INTRODUCTION}

Psychedelic substances, such as lysergic acid diethylamide (LSD) and psilocybin, are wellknown for their ability to alter states of consciousness through their interaction with serotonin neurotransmitter systems (Glennon, Titeler, \& McKenney, 1984; Jacobs, 1987). These hallucinogens might induce heightened awareness of one's self and surroundings, increases in emotionality, and physiological changes, including pupil dilation, dizziness, and loss of appetite (Grinspoon \& Bakalar, 1983). Not all users will experience the same effects, potentially due to the impact of set (aspects of the individual) and setting (aspects of the environment) (Leary, Litwin, \& Metzner, 1963). As of 2010, approximately 32 million Americans used LSD, psilocybin, mescaline, or peyote in their lifetimes (Krebs \& Johansen, 2013). Moreover, lifetime

${ }^{*}$ Corresponding author. 1400 Washington Avenue SS 217, Albany, 12203, NY, USA. Tel.: (+1) 518442 4820. E-mail: Baltman@albany.edu hallucinogen use in the United States has increased since 2001, possibly due to the amplified curiosity about this class of substances (Shalit, Rehm, \& Lev-Ran, 2019). While many individuals use these substances recreationally, new research reveals clinical utility of these drugs in treating depression, anxiety, posttraumatic stress disorder (PTSD), and substance use disorders (Bogenschutz \& Johnson, 2016; Carhart-Harris et al., 2016; Mithoefer et al., 2018; Ot’alora et al., 2018; Ross et al., 2016; Rucker, Jelen, Flynn, Frowde, \& Young, 2016; dos Santos, Bouso, Alcázar-Córcoles, \& Hallak, 2018; Morgan, McAndrew, Stevens, Nutt, \& Lawn, 2017). 
These recent findings call for an in-depth exploration of individual substances within this class of drugs, and why people might choose one over another.

\section{Ayahuasca}

Ayahuasca is a tea with psychoactive properties derived from the plants Banisteriopsis caapi and Psychotria viridis. The main psychoactive properties in ayahuasca result from the combination of dimethyltryptamine, or DMT, and beta-carboline alkaloids, which allow for the oral consumption of DMT to be psychoactive (McKenna, 2004; McKenna, Towers, \& Abbott, 1984; Riba, Valle, Urbano, Yritia, Morte, \& Barbanoj, 2003). Many citizens of South America turn to ayahuasca to alleviate illness and promote spiritual or religious experiences, although use has become more widespread among individuals seeking personal growth or emotional healing (Labate \& Cavnar, 2014; Schmid, 2012; Tupper, 2008; Winkelman, 2011). Ingestion typically occurs during ceremonies or retreats, often led by trained shamans (Grunwell, 1998; Metzner, 1999). Some ceremonies encourage socialization among groups, with singing and music, while others promote a quieter and more introspective experience (Harris \& Gurel, 2012; Luna, 1986, 2011; Winkelman, 2001). The interaction of the shaman and the specifics of the ritual set the tone for the ingestion experience.

Ayahuasca produces a host of subjective effects, usually within an hour of ingestion (Riba et al., 2001). Users might experience intense, dream-like hallucinations or increased sensitivity to auditory stimuli (Domínguez-Clavé et al., 2016; Riba et al., 2001). Not all users experience these effects, perhaps suggesting an unpredictable nature of hallucinogens in general (Domínguez-Clavé et al., 2016; Swanson, 2018). Ayahuasca might also induce cognitive changes, producing intense emotional reactions and generating new perspectives (Frecska, Bokor, \& Winkelman, 2016; Uthaug et al., 2018). Other users report experiencing frightening, paranoia-like states, which might instill regret about the user's choice to participate in the ceremony (Kjellgren, Eriksson, \& Norlander, 2009). Typically, adverse reactions subside after short periods; verbal encouragement can help to provide relief in some circumstances (Riba et al., 2001). Additionally, many individuals experience nausea or vomiting after ingestion (Riba et al., 2001; Shanon, 2002). While these effects are discouraging to some, others cite purging as a necessary component of ayahuasca use, allowing for the release of psychological suffering and summoning a meaningful perspective on past experiences (Kavenská \& Simonová, 2015; Loizaga-Velder, 2013). In spite of these physical shortterm side effects, healthy users tolerate ayahuasca well, and long-term negative reactions are rare in laboratory settings (dos Santos, Balthazar, Bouso, \& Hallak, 2016).

Although literature suggests ayahuasca's effects may parallel the impact of other psychedelics including LSD and mushrooms, some work suggests otherwise. One qualitative study suggests that individuals should be experienced with the effects of hallucinogens before trying ayahuasca (Wiecko, Thompson, \& Parham, 2017). In fact, many ayahuasca users report experience with other psychedelics including LSD and mushrooms (Harris \& Gurel, 2012). Individuals also rated the effects of ayahuasca as stronger than more typical hallucinogens (Lawn et al., 2017). Moreover, a recent study of "God encounter experiences" suggests that ayahuasca users reported more positive life outcomes after their God encounter, including enhanced social relationships and more positive self-views, compared to those who used LSD or psilocybin (Griffiths, Hurwitz, Davis, Johnson, \& Jesse, 2019). Taken together, these results suggest discernible features of the ayahuasca experience potentially render it unique from more traditional psychedelics; however, given the paucity of research on this topic, more work appears justified. These variations in subjective effects might influence individuals' likelihood to use ayahuasca or other hallucinogens in the future. Should the effects prove discernably unique, participants might benefit from an education about the novel facets of the tea.

\section{The influence of expectancies on future hallucinogen use}

Substance use expectancies are individuals' beliefs about how a substance might influence their subjective experience (McPherson \& Harris, 2015). Positive expectancies typically covary with more frequent and heavy substance use, while negative expectancies often predict abstinence (Gaher \& Simons, 2007). In both the cannabis and alcohol literature, expectancies about substance effects are associated with either drug-taking or avoidance behaviors (Christiansen, Smith, Roehling, and Goldman, 1989; Jones, Corbin, \& Fromme, 2001; Metrik et al., 2009; Schafer \& Brown, 1991). Very little work has directly examined the role of hallucinogen expectancies and their influence on users' subjective experiences and future ingestion behavior. Positive expectancies about the effects of psilocybin covary with more enjoyable ingestion experiences (Metzner, Litwin, \& Weil, 1965). Previous experiences with classic hallucinogens might influence present psilocybin use (Studerus, Gamma, Kometer, \& Vollenwider, 2012). To the author's knowledge, the impact of expectancies about ayahuasca and their role in determining future ayahuasca use remains unexamined. For this reason, an exploration of the role of expectancies and other predictors on the use of ayahuasca or other hallucinogens appears warranted.

\section{The present study}

Perhaps due to the sacred nature of the ayahuasca ceremony, research is lacking about individuals' experiences with the psychoactive tea and how it differs from other substances. Current research cannot identify who might seek out ayahuasca rather than other hallucinogens.

The present study queried users about their experience with ayahuasca (and whether it differed from other substances) in an effort to predict individual substance choices. We hypothesized that ayahuasca use would covary with a greater connection to nature than other psychedelic drugs. Ayahuasca might also produce more undesirable physical reactions, such as vomiting, 
nausea, and diarrhea than other hallucinogens, which might discourage later use. Alternatively, some individuals might cite these physical effects as meaningful components of the ayahuasca experience, which could positively relate to their future use. Additionally, we believed that the sum of these experiences would correlate with individuals' willingness to ingest ayahuasca over other hallucinogens in the future. Should these findings hold true, we might better understand the facets of the ayahuasca experience that compel individuals to choose ayahuasca over other psychedelics.

\section{METHODS}

\section{Participants and procedure}

Participants were recruited via community Facebook pages pertaining to ayahuasca and other hallucinogen use. In these Facebook groups, we posted a SurveyMonkey (www. surveymonkey.com) link inviting interested individuals to share their thoughts about ayahuasca and other hallucinogens. SurveyMonkey is a secure, internet-based data collection tool that allows researchers to develop and distribute surveys to willing participants. Upon clicking the SurveyMonkey link, participants received information about the study's aims and were prompted to provide informed consent if they were interested in participating in our study. Only individuals who were at least 18 years old were invited to complete the survey. Other researchers have used similar methodology to recruit participants for studies on hallucinogens (Carbonaro et al., 2016).

Invited participants $(\mathrm{N}=152)$ were then asked to complete an online survey assessing demographic variables, ayahuasca and other hallucinogen use, beliefs about ayahuasca's novelty compared to other hallucinogens, and future use intentions. For the purposes of this study, only individuals who used ayahuasca at least once $(\mathrm{N}=139)$ were included in data analysis. All study procedures were completed in accordance with and approved by the local Institutional Review Board.

\section{Measures}

Demographics of study participants. The majority of the sample was male (54.3\%) and reported an age between 40 and 49 (29.5\%). Participants were predominantly white $(87.1 \%)$ and highly educated, with $29 \%$ reporting holding a bachelor's degree and $29.7 \%$ reporting having a graduate degree.

Ayahuasca use. Participants reported on their lifetime use of ayahuasca $(\mathrm{M}=43.96$, Median $=9.00, \mathrm{SD}=139.28)$ and how many years $(\mathrm{M}=0.58$, Median $=0.00, \mathrm{SD}=1.838)$ and months $(\mathrm{M}=2.77$, Median $=2.00, \mathrm{SD}=2.77)$ had elapsed since their most recent ingestion.

Hallucinogen use. Participants also reported on their lifetime use of other LSD, mushrooms, DMT, and other substances, as seen in Table 1.
Table 1. Lifetime use of hallucinogens

\begin{tabular}{lccc}
\hline Hallucinogen & Mean (SD) & Median & Range \\
\hline LSD & $27.51(104.99)$ & 1.00 & $0-1,000$ \\
Mushrooms & $25.64(94.08)$ & 5.00 & $0-1,000$ \\
MDMA & $19.55(82.7)$ & 0.00 & $0-5$ \\
DMT & $3.66(11.21)$ & 0.00 & $0-100$ \\
Peyote & $2.34(17.37)$ & 0.00 & $0-200$ \\
Ketamine & $2.18(7.80)$ & 0.00 & $0-800$ \\
Mescaline & $2.00(6.317)$ & 0.00 & $0-60$ \\
Salvia & $1.58(5.50)$ & 0.00 & $0-50$ \\
Psilocybin & $0.19(1.027)$ & 0.00 & $0-10$ \\
Ibogaine & $0.17(0.63)$ & 0.00 & $0-5$ \\
PCP & $0.10(0.643)$ & 0.00 & $0-6$ \\
DXM & $0.10(0.634)$ & 0.00 & $0-5$ \\
DOT & $0.01(0.087)$ & 0.00 & $0-1$ \\
\hline
\end{tabular}

Novelty of Ayahuasca Scale. A separate sample of 19 participants helped generate items by responding to the prompt, "How is ayahuasca different from other hallucinogens like mushrooms or LSD?" in a group setting. Of these 19 participants, 11 were women, approximately $74 \%$ were Caucasian, their mean age was approximately 43 , and they were also highly educated ( $\sim 95 \%$ hold a Bachelor's degree or higher). Each participant had used ayahuasca at least twice and used other hallucinogens, such as LSD and mushrooms, at least once. On average, endorsements of use were much higher than these selection criteria. Initial ideas led to 44 items, which were collapsed to 22 based on similar content. These 22 were then reviewed by two people ( 1 female, both Caucasian, $\mathrm{M}_{\mathrm{age}}=48.5$, both hold graduate degrees) familiar with scale construction who had used ayahuasca, LSD, and mushrooms at least six times each. These individuals reduced the list to 19 items based on ambiguity or overlapping content. These 19 items were then reviewed by a shaman trainee (male, age $=45$, Caucasian, Bachelor's degree) who had used ayahuasca approximately 700 times and mushrooms and LSD approximately 10 times each. For demographics of scale contributors, see Table 2. The final list of items used in this scale appears in Table 3 Participants were presented with the prompt, "Compared to 'typical hallucinogens', ayahuasca..." and were asked to respond to the items on a Likert scale from -2 (completely false) to 2 (completely true). Cronbach's alpha for these original 19 items was 0.784 .

Likelihood of future use. Participants reported their likelihood to ingest ayahuasca again in their lifetime, the next year, the next 3 months, and the next month, ranging from -3 = "Impossible" to $3=$ "Definitely will happen". Participants also reported on their likelihood to use other hallucinogens. We generated a difference variable by subtracting "likelihood to use other hallucinogens" from "likelihood to use ayahuasca," indicating how likely participants were to use ayahuasca over other hallucinogens in their lifetime, the next year, the next 3 months, and the next month. We then combined these four variables (Cronbach's $\alpha=0.897)$ to generate one composite variable, indicating participant likelihood of using ayahuasca over other 
Table 2. Demographics of contributors to scale items

\begin{tabular}{|c|c|c|c|}
\hline Contributors & Mean (SD) & Median & Range \\
\hline \multicolumn{4}{|c|}{$\begin{array}{l}\text { Initial contributors }(N=19) \\
\text { Lifetime use of }\end{array}$} \\
\hline Ayahuasca & $42.58(10.93)$ & 43.00 & $26-61$ \\
\hline LSD & $17.11(12.50)$ & 11.00 & $0-50$ \\
\hline Mushrooms & $26.79(15.11)$ & 22.00 & $9-60$ \\
\hline MDMA & $12.26(8.79)$ & 11.00 & $0-30$ \\
\hline DMT & $1.58(2.36)$ & 0.00 & $0-8$ \\
\hline Peyote & $5.68(6.15)$ & 4.00 & $0-27$ \\
\hline Ketamine & $2.52(3.63)$ & 0.00 & $0-10$ \\
\hline Mescaline & $0.21(0.63)$ & 0.00 & $0-2$ \\
\hline Salvia & $10.79(8.89)$ & 10.00 & $0-30$ \\
\hline \multicolumn{4}{|c|}{ Item reviewers $(N=2)$} \\
\hline Ayahuasca & $57.00(12.73)$ & 57.00 & $48-66$ \\
\hline LSD & $22.50(14.85)$ & 22.50 & $12-33$ \\
\hline Mushrooms & $23.50(7.78)$ & 23.50 & $18-29$ \\
\hline MDMA & $7.00(4.24)$ & 7.00 & $4-10$ \\
\hline DMT & $1.00(1.41)$ & 1.00 & $0-2$ \\
\hline Peyote & $4.50(6.36)$ & 4.50 & $0-9$ \\
\hline Ketamine & $0.00(0.00)$ & 0.00 & 0 \\
\hline Mescaline & $0.00(0.00)$ & 0.00 & 0 \\
\hline Salvia & $18.50(3.54)$ & 18.50 & $16-21$ \\
\hline \multicolumn{4}{|c|}{ Shaman trainee $(N=1)$} \\
\hline Ayahuasca & $\sim 700$ & & \\
\hline LSD & $\sim 100$ & & \\
\hline Mushrooms & $\sim 200$ & & \\
\hline MDMA & $\sim 50$ & & \\
\hline DMT & 5 & & \\
\hline Peyote & 1 & & \\
\hline Ketamine & $\sim 100$ & & \\
\hline Mescaline & 3 & & \\
\hline Salvia & $\sim 100$ & & \\
\hline
\end{tabular}

hallucinogens in the future. Thus, this variable served as an index of the magnitude of intentions to use ayahuasca over and above the intentions to use other hallucinogens in all subsequent analyses.

\section{Data analytic plan}

First, we conducted a series of one-sample $t$-tests against 0 to examine whether participants believed that ayahuasca produced significantly different effects from other hallucinogens. For these 19 analyses, we considered a $P$-value of $P<$ $0.001(0.05 / 19)$ to be significant (Wilcox, 2013). Next, we performed an exploratory factor analysis (EFA) of the Novelty of Ayahuasca Scale to identify factorable components of individuals' experiences with the substance. Additionally, we conducted a multiple regression to determine whether the factors yielded by the EFA accounted for a significant amount of unique variance in preference for ayahuasca over other hallucinogens, while controlling for the influence of gender and lifetime ayahuasca use. Finally, we examined correlations among the factors of the Novelty of
Ayahuasca Scale, the global scale after removing unfit items, and participant likelihood of using ayahuasca again over other hallucinogens.

\section{RESULTS}

\section{Ayahuasca versus other hallucinogens}

One sample $t$-tests indicated that all ayahuasca experience variables were significantly different from $0, P<0.001$, $\left(t_{(133-136)}\right.$ ranging from 6.212 to 27.658), except for "almost requires being out in nature" $\left(t_{(136)}=2.033, P=0.044\right)$, "has the potential to lead to darker thoughts" $\left(t_{(135)}=1.459, P=0.147\right)$ and "can create more negative thoughts or emotions" $\left(t_{(134)}=-2.276\right.$, $P=0.024$; See Table 3). Cohen's d effect sizes ranged from small to very large $(d=0.14-2.18)$.

\section{Novelty of Ayahuasca Scale}

We conducted an exploratory factor analysis (EFA) using a principal-axis factor extraction to establish the factor structure of 19 items related to participants' experiences using ayahuasca compared to other hallucinogens. The KaiserMeyer-Olkin (KMO) measure of sampling adequacy (0.72) and Bartlett's test of sphericity $(\chi 2=675.01, P<0.001)$ demonstrated that these data were factorable. A visual inspection of the scree plot and examination of eigenvalues greater than 1.00, revealed that a three-factor solution was appropriate (eigenvalues $=4.03,2.92$, and 1.65). To interpret these three factors, we used a promax rotation. After running this preliminary 3-factor model, we noted that seven of the original variables did not map onto these three factors ("almost requires being out in nature," "could create strong visuals or none at all," "depends more on songs and music," "is less recreational," "is more likely to have no impact at all," "makes bigger demands of users," and "leads to thoughts of being out in the open or wilderness"). Removal of these seven items decreased Cronbach's alpha from 0.78 to 0.69 . The Kaiser-Meyer-Olkin (KMO) measure of sampling adequacy remained the same (0.72) and Bartlett's test of sphericity remained significant $(\chi 2=434.74, P<0.001)$. An examination of extracted communalities suggested that these remaining items mapped onto the three factors well. A threefactor model still appeared justified (eigenvalues $=3.03,2.62$, 1.38 ), and accounted for $58.60 \%$ of the total variance.

Factor 1 (five items) represented positive aspects of users' ayahuasca experiences that increased their connection to nature and their shaman. Factor 2 (four items) signified aspects of users' experiences that led to more negative or unpredictable reactions. Factor 3 (three items) characterized physical reactions associated with ayahuasca use. The factors accounted for $22.25 \%, 21.85 \%$, and $11.49 \%$ of the total scale variance respectively. Table 4 demonstrates observed factor loadings for each item. Indices of internal consistency for the three factors appeared to be within the acceptable range (Cronbach's $\alpha=0.76,0.74$, and 0.70 , respectively). 
Table 3. Results of one sample $t$-tests

\begin{tabular}{|c|c|c|c|}
\hline Variable & Mean (SD) & $t$-Value & Abs Value of Cohen's d \\
\hline $\begin{array}{l}\text { Can seem particularly great with the right } \\
\text { facilitators/shaman }\end{array}$ & $1.51(0.63)$ & $27.66^{*}$ & 2.18 \\
\hline Could create strong visuals or none at all & $1.43(0.76)$ & $22.17^{\star}$ & 1.80 \\
\hline Is less "recreational" & $1.47(0.92)$ & $18.67^{*}$ & 1.62 \\
\hline Is more of a medicine & $1.39(0.80)$ & $20.50^{*}$ & 1.61 \\
\hline Makes people throw up more often & $1.21(0.74)$ & $18.85^{*}$ & 1.59 \\
\hline Seems closer to other plants and the earth & $1.31(0.83)$ & $18.13^{*}$ & 1.55 \\
\hline Can cause more nausea & $1.20(0.80)$ & $17.65^{*}$ & 1.47 \\
\hline Creates results that are harder to predict & $1.20(0.91)$ & $15.33^{*}$ & 1.30 \\
\hline Has more of a connection to the earth & $1.11(0.90)$ & $14.48^{\star}$ & 1.26 \\
\hline Is more likely to have no impact at all & $-1.20(1.07)$ & $-13.10^{*}$ & 1.17 \\
\hline Changes more with the shaman & $0.95(0.83)$ & $13.31^{\star}$ & 1.13 \\
\hline Makes bigger demands of users & $0.80(1.07)$ & $8.74^{*}$ & 0.79 \\
\hline $\begin{array}{l}\text { Leads to thoughts of being out in the open or in } \\
\text { the wilderness }\end{array}$ & $0.60(0.84)$ & $8.21^{\star}$ & 0.73 \\
\hline Depends more on songs and music & $0.62(0.93)$ & $7.85^{\star}$ & 0.63 \\
\hline Leads to diarrhea more often & $0.63(1.11)$ & $6.54^{*}$ & 0.56 \\
\hline Can be more terrifying & $0.60(1.11)$ & $6.21^{\star}$ & 0.55 \\
\hline Almost requires being in nature & $0.20(1.18)$ & 2.03 & 0.22 \\
\hline Can create more negative thoughts or emotions & $-0.21(1.06)$ & -2.28 & 0.15 \\
\hline Has the potential to lead to darker thoughts & $0.14(1.11)$ & 1.46 & 0.14 \\
\hline
\end{tabular}

Prompt: How true is each of these items? "Compared to 'typical hallucinogens', ayahuasca...”.

Scale: -2 (completely false), -1 (mostly false), 0 (neither true nor false), 1 (mostly true), 2 (completely true).

Note: ${ }^{\star} P<0.001$.

\section{Ayahuasca over other hallucinogens}

We regressed preference for ayahuasca on the three factors of the Novelty of Ayahuasca Scale while controlling for gender and lifetime ayahuasca use. After removal of seven outliers, the data met assumptions for linearity, normality, heteroscedasticity, and multicollinearity. The regression was significant $\left(F_{(5,113)}=3.97, P<0.01\right.$, adjusted $\left.R^{2}=0.11\right)$. The adjusted $R^{2}$ value suggests that approximately $11 \%$ of the variance in the dependent variable could be accounted for. Only factor $1(B=0.69, t=2.99, P<0.01)$ and factor 3 $(B=-0.89, t=-2.68, P<0.01)$ had significant main effects. The squared semi partial coefficients revealed that removal of factors 1 and 3 from the regression equation would yield a 7 and $6 \%$ decrease in predictive utility, respectively. Participant gender, lifetime ayahuasca use, and factor 2 were not significant (See Table 5).

\section{Predicting ayahuasca and other substance use in the future}

The total score on The Novelty of Ayahuasca Scale (sum of all 12 items with items from factors 2 and 3 reverse-scored; Cronbach's alpha $=0.661$ ) significantly positively covaried with intentions to use ayahuasca over other hallucinogens in the future, and intentions to use ayahuasca again in the

Table 4. Factor analysis of ayahuasca experiences constructs

\begin{tabular}{lrrr}
\hline Item & Factor 1 & Factor 2 & Factor 3 \\
\hline Changes more with the shaman & $\mathbf{0 . 4 5 7}$ & 0.036 & -0.130 \\
Has more of a connection to the earth & $\mathbf{0 . 7 6 3}$ & -0.002 & 0.037 \\
Is more of a medicine & $\mathbf{0 . 7 5 1}$ & -0.022 & 0.017 \\
Seems closer to other plants and the earth & $\mathbf{0 . 5 3 3}$ & 0.032 & -0.017 \\
Can seem particularly great with the right facilitators or & $\mathbf{0 . 7 0 5}$ & -0.102 & 0.029 \\
$\quad$ shaman & & \\
Creates results that are harder to predict & 0.332 & $\mathbf{0 . 4 6 9}$ & -0.022 \\
Can be more terrifying & -0.009 & $\mathbf{0 . 5 5 3}$ & 0.212 \\
Has the potential to lead to darker thoughts & -0.142 & $\mathbf{0 . 8 3 1}$ & -0.058 \\
Can create more negative thoughts or emotions & -0.010 & $\mathbf{0 . 6 7 7}$ & -0.029 \\
Can cause more nausea & -0.061 & 0.063 & $\mathbf{0 . 6 9 9}$ \\
Leads to diarrhea more often & 0.012 & 0.064 & $\mathbf{0 . 5 7 0}$ \\
Makes people throw up more often & 3.03 & -0.095 & 2.62 \\
Eigenvalues & 25.25 & 21.85 & 1.38 \\
\% of Variance & & $\mathbf{0 . 7 8 3}$ \\
\hline
\end{tabular}

Prompt: How true is each of these items? "Compared to 'typical hallucinogens', ayahuasca...".

Scale: -2 (completely false), -1 (mostly false), 0 (neither true nor false), 1 (mostly true), 2 (completely true).

Bolded values indicate factor loadings of items that comprise each factor. 
Table 5. Predicting preference for ayahuasca over other hallucinogens from gender, lifetime ayahuasca use, and factors 1,2 , and 3

\begin{tabular}{lcccrrr}
\hline Predictor & $\begin{array}{c}\text { Preference for } \\
\text { Ayahuasca }\end{array}$ & $\mathrm{B}$ & $S E$ & $\beta$ & \multicolumn{1}{c}{ CI $(95 \%)$} & $s r^{2}$ \\
\hline Gender & 1.45 & 2.00 & 1.38 & 0.13 & $-0.74,4.73$ & 0.02 \\
Lifetime ayahuasca use & 1.24 & 0.03 & 0.02 & 0.11 & $-0.02,0.07$ & 0.01 \\
Factor 1 & $2.99^{*}$ & 0.69 & 0.23 & 0.26 & $0.23,1.14$ & 0.07 \\
Factor 2 & 0.46 & 0.10 & 0.23 & 0.04 & $-0.34,0.55$ & 0.00 \\
Factor 3 & $-2.68^{*}$ & -0.89 & 0.33 & -0.25 & $-1.54,-0.23$ & 0.06 \\
Intercept & & -2.58 & 3.05 & & & \\
\hline
\end{tabular}

Note: ${ }^{\star} P<0.01$.

future, but negatively related to intentions to use other hallucinogens in the future. Factor 1 of the scale was positively related to individuals likelihood of future ayahuasca use over other hallucinogens and negatively related to intentions to use other hallucinogens in the future. Factor 1 did not correlate significantly with simple intentions to use ayahuasca. Factor 2 was not significantly related to any measure of intentions of future use. Factor 3 not only varied significantly (and inversely) with intentions to use ayahuasca in the future, it also covaried negatively with intentions to use ayahuasca over other hallucinogens. Additionally, using the method for comparing correlated correlation coefficients proposed by Meng, Rosenthal, and Rubin (1992), we found that the relation between ayahuasca preference and factor 3 was significantly stronger than the association between ayahuasca preference and factor $1(P<0.001)$.

Alternatively, two astute and anonymous reviewers pointed out that factor 3 might not necessarily be interpreted as negative by all users; thus, we recalculated the global scale with only items from factor 2 reverse-scored (Cronbach's alpha $=0.404$ ). As expected, all three factors significantly positively covaried with this global score. However, this global score did not significantly covary with any of the three future use variables. Correlations among study variables appear in Table 6.

\section{DISCUSSION}

Few studies address differences among hallucinogens and their role in intentions to use them. The present study sought to determine if novel aspects of the ayahuasca experience contributed to hypothetical decisions to use it again and to use it again rather than other hallucinogens. This information can help researchers focus on ways to minimize harm and let users make informed decisions about their use. Overall, our findings confirm that expectancies about ayahuasca's effects predict intentions to use the psychoactive brew again, much like research has revealed for other substances (Goldman, Brown, \& Christiansen, 1987; Hayaki, Hagerty, Herman, de Dios, Anderson, \& Stein, 2010; Metrik et al., 2009; Metzner et al., 1965). Moreover, these expectancies also predict intentions to use ayahuasca over other hallucinogens.

Respondents reported striking differences between ayahuasca and typical hallucinogens. Two items that specifically mention that role of the shaman ("changes more with the shaman" and "can seem particularly great with the right facilitators or shaman") showed large effects (Cohen's $d=1.13$ and 2.18, respectively), confirming previous work (Kavenská \& Simonová, 2015). Participants also believed ayahuasca "is more of a medicine" (Cohen's $d=1.61$ ) and "is less 'recreational"' (Cohen's $d=1.62$ ) than other hallucinogens, as other work has shown (Harris \& Gurel, 2012). Users also believed that ayahuasca increased their connectivity to earth and nature more so than other hallucinogens (Cohen's $d=1.55$ and 1.26 , respectively), perhaps because of its plant origin. The sum of these items created factor 1 of the Novelty of Ayahuasca Scale and covaried positively with intentions to use ayahuasca over other hallucinogens in the future.

Participants also reported that the psychoactive brew is unpredictable, more likely to "create results that are harder

Table 6. Table of correlations

\begin{tabular}{|c|c|c|c|c|c|c|c|c|}
\hline Variables & Mean (SD) & 1 & 2 & 3 & 4 & 5 & 6 & 7 \\
\hline 1. Factor 1 & $6.27(2.88)$ & & & & & & & \\
\hline 2. Factor 2 & $1.69(3.17)$ & 0.110 & & & & & & \\
\hline 3. Factor 3 & $3.02(2.12)$ & -0.006 & $0.341^{\star *}$ & & & & & \\
\hline $\begin{array}{l}\text { 4. Global Scale (with F2 and F3 reverse } \\
\text { scored) }\end{array}$ & $1.52(5.06)$ & $0.457^{\star \star}$ & $-0.685^{\star *}$ & $-0.654^{\star \star}$ & & & & \\
\hline 5. Global Scale (with F2 reverse scored) & $11.14(5.43)$ & $0.594^{* *}$ & $0.780^{* *}$ & $0.586^{\star *}$ & $-0.396^{* *}$ & & & \\
\hline 6. Intentions to use aya in the future & $5.26(5.37)$ & 0.095 & -0.100 & $-0.251^{\star *}$ & 0.136 & -0.093 & & \\
\hline $\begin{array}{l}\text { 7. Intentions to use other halls in the } \\
\text { future }\end{array}$ & $2.31(6.67)$ & $-0.207^{\star}$ & -0.022 & 0.148 & $-0.193^{\star}$ & -0.061 & 0.139 & \\
\hline $\begin{array}{l}\text { 8. Intentions to use aya over other halls } \\
\text { in the future }\end{array}$ & $2.95(7.98)$ & $0.242^{* *}$ & -0.048 & $-0.294^{\star *}$ & $0.258^{* *}$ & -0.006 & $0.557^{\star *}$ & $-0.745^{\star *}$ \\
\hline
\end{tabular}

Note: ${ }^{\star} P<0.05,{ }^{\star \star} P<0.05$. 
to predict", and "can be more terrifying" than other hallucinogens (Cohen's $d=1.30$ and 0.55 , respectively). These variables and two others addressing the negative cognitions produced by ayahuasca ("has the potential to lead to darker thoughts" and "can create more negative thoughts or emotions") comprised factor 2. Factor 2 did not significantly relate to ayahuasca preference in our bivariate correlations or multiple regressions. Perhaps users consider these variable effects in combination with the perceived benefits of the psychoactive tea and they cancel each other out. Alternatively, individuals might recognize the potential for negative cognitions with all substances within this class; thus, it might not be predictive of whether or not someone uses ayahuasca again or over other hallucinogens.

Respondents also experience more nausea, vomiting, and diarrhea while using ayahuasca compared to other psychedelics (Cohen's $d=1.47,1.59$, and 0.56 , respectively). These gastro-intestinal symptoms, which constitute factor 3 , are inversely related to individuals' intentions to use ayahuasca over other hallucinogens in the future. Although some users might cite these experiences as necessary and meaningful components of the ayahuasca ceremony, in our work these physical side effects inhibit a preference for ayahuasca.

In combining these three factors, we sought to generate a scale which might educate interested individuals about the unique effects of ayahuasca compared to other hallucinogens. While one version of the global scale (with both factors 2 and 3 reverse-scored) significantly predicts who might choose ayahuasca over other hallucinogens, another version (with only factor 2 reverse scored) did not significantly relate to any future use variables. Relatedly, when we used this alternative calculation, the internal reliability dropped drastically. Future work should gather more information about how users perceive the ayahuasca-induced physical effects (e.g., vomiting, diarrhea) to determine whether these items should be reverse-scored before being aggregated into the global score. Nevertheless, the three unique factors of the scale have important relations to future use variables; individuals' responses to these items might help us predict what hallucinogen they are most inclined to use in the future.

Three items did not fit prevalent stereotypes about ayahuasca. Two items related to negative, dark, or gloomy cognitions failed to differ from zero on their endorsements ("has the potential to lead to darker thoughts" and "can create more negative thoughts or emotions"). This result contrasts with previous papers where users reported greater negative effects after ingesting ayahuasca than when using LSD or mushrooms (Lawn et al., 2017). Future work might benefit from more specific answer options to allow individuals to report nuances about their ayahuasca experiences. Furthermore, the only other item that did not differ significantly from 0 ("almost requires being out in nature"), might suggest a common feature of hallucinogen use - that an outdoor environment might enhance experience with any of them (Shanon, 2002). Although we are reluctant to argue from a null result, this result might reassure those who are contemplating ayahuasca consumption if they are concerned about a more aversive or gloomy experience than that created by other hallucinogens.

\section{Potential contributors to item selection}

A number of items from the original Novelty of Ayahuasca Scale did not map onto the three factors in our EFA. Further examination of these items yielded several hypotheses about the meaning of their exclusion. Some items which were excluded may have been too similar to items that were included. For instance, the correlation between "better with the right shaman" and "can seem particularly great with the right shaman" is $r=0.425$. Future work should examine nuances between similar items to consider if they should be modified to gain a more detailed picture about the ayahuasca experience.

Three items related to set and setting ("almost requires being out in nature", "depends more on songs and music", and "leads to thoughts of being out in the open or wilderness") did not map onto any of the observed factors in the EFA. While two of these three items yielded significant t-values in our independent t-tests, "almost requires being out in nature" did $\operatorname{not}(t=2.03, P=0.044)$. It is possible that these items did not uniquely relate to individuals' ayahuasca experiences and more broadly represent important attributes of psychedelic substances. Similarly, the item "could create strong visuals or none at all" yielded a significant t-value with a large effect size $(t=22.17$, Cohen's $d=1.80)$, but did not map onto any of the observed EFA factors. This item may also not be specific enough to ayahuasca to warrant inclusion in the final Novelty of Ayahuasca Scale, as many psychedelics produce visual hallucinations. A more in-depth exploration of facets of the hallucinogen experience that are unique to ayahuasca appears warranted.

\section{Potential therapeutic benefits of ayahuasca}

Many users might seek ayahuasca for its purported medicinal and healing effects, thus an examination of the literature on clinical applications of ayahuasca is necessitated. Across numerous randomized control and open label trials, ayahuasca demonstrates strong antidepressant and anxiolytic effects (Osório et al., 2015; Palhano-Fontes et al., 2019; Sanches et al., 2016). Preliminary evidence suggests ayahuasca might help to inhibit problematic substance use, especially when used in conjunction with psychotherapy (Hamill, Hallak, Dursun, \& Baker, 2018; Loizaga-Velder \& Pazzi, 2014; Thomas, Lucas, Capler, Tupper, \& Martin, 2013). Current work indicates ayahuasca poses limited risk to healthy adults across acute and long-term administration; future work should examine ayahuasca's safety among pregnant women, those with health problems, and those consuming other drugs or supplements (dos Santos, 2013; dos Santos et al., 2016). Despite being well-tolerated overall, reported adverse effects during consumption in clinical settings include anxiety, nausea, and vomiting (dos Santos et al., 2016; Osório et al., 2015). Individuals should weigh these potential outcomes against the expected benefits to make an informed decision about personal ayahuasca consumption. 


\section{Limitations}

Like many computer-administered, cross-sectional, selfreport studies of illicit psychoactive substance use and relevant correlates, these data require cautious interpretation. Our predominantly Caucasian, middle-aged, highly educated sample responded via computer on a single occasion long after subjective effects of ayahuasca had likely dissipated. Despite our concerted efforts to assure anonymity, legal sanctions against hallucinogens and imperfections in recall might alter participant reports. A large, diverse sample who could complete measures without access to computers could help reveal if the new scale's factor structure and the relations with intentions of future use applies to a wider range of people. A longitudinal design that permitted follow-ups of extended duration and confirmation of subsequent use of ayahuasca or other hallucinogens would certainly provide an improved test of these hypotheses. Additionally, qualitative reports could help clarify the nature of differences between various types of hallucinogens. Due to the importance of the highly subjective experience of these substances, future studies might employ interview formats to gain a more nuanced perspective about the unique qualities of specific drugs.

In addition, although individuals within this sample were relatively experienced with hallucinogens, few endorsed lifetime use of psilocybin, DXM, ibogaine, and DOT. Participants were most experienced with LSD, mushrooms, and MDMA; thus, our results are mostly generalizable to those substances. Future work might target individuals who have used ayahuasca in addition to other less popular substances to confirm whether these findings apply to those drugs as well. Relatedly, ayahuasca was the most frequently used hallucinogen among this sample, suggesting the possibility that individuals exaggerated the positive effects of this substance compared to other hallucinogens, due to its familiarity. Likewise, our work may be subject to selection bias in that only individuals with strongly positive or strongly negative attitudes toward ayahuasca might have self-selected to enroll in our study. To strengthen future attempts at replication, researchers might survey all willing participants after an ayahuasca ceremony to gain a more objective view of all individuals' experiences with the psychoactive tea.

\section{CONCLUSION}

Taken together, factor 3 (physical reactions) negatively covaries with individuals' intentions to use ayahuasca in the future. Ayahuasca-induced gastro-intestinal effects were associated with a decreased desire to use the substance in the future. Alternatively, factor 1 (positive connection to nature and other people) was negatively associated with a desire to use other hallucinogens in the future. This suggests that individuals' positive experiences with ayahuasca might decrease their desire for other hallucinogens. Finally, looking at users' intentions to seek out ayahuasca over more traditional psychedelic substances, it appears that factor 1 relates positively while factor 3 correlates negatively. Ayahuasca consumers, who experience more positive effects and increased connectiveness to the earth, might prefer to use the psychoactive tea again over other hallucinogens in their lifetime. Conversely, individuals who do not tolerate nausea, vomiting, or diarrhea well might be more inclined to use other hallucinogenic substances. Moreover, factor 3 was more strongly related to ayahuasca preference than factor 1 . This finding intimates that the negative side effects of using ayahuasca might outweigh the positives when individuals consider using the substance again. Factor 2 (unpredictable or negative cognitive responses) did not significantly relate to individuals' proclivities toward ayahuasca or other hallucinogens, perhaps because it underscores the variable nature of all hallucinogenic substances, which might generate apprehension in users. These results intimate that we might be able to predict which hallucinogenic substance individuals will prefer in the future based on their previous experiences with ayahuasca.

In summary, the Novelty of Ayahuasca Scale reveals distinct ways in which users' experiences with ayahuasca differ from more traditional hallucinogens. Participant reports mapped onto three main factors: a positive connection to nature and other people, unpredictable or negative cognitive responses, and physical reactions. These unique aspects of the ayahuasca experience map onto individuals' willingness to use the psychoactive tea again in the future over other hallucinogens. Future work with a more diverse sample, collateral reporters, and longitudinal follow-up could confirm these findings and add to their generalizability and validity. The creation of this scale might aid some users in determining whether they should try ayahuasca based on the experiences of others. For individuals who might seek out ayahuasca for medicinal, recreational, or perspective-raising purposes, the Novelty of Ayahuasca Scale might serve as an educational resource to help them decide if the psychoactive tea is the right substance for their intentions. Especially among those seeking relief from depression, anxiety, and trauma, the scale, in combination with the existent clinical literature, can allow these individuals to make an informed choice about the perceived pros and cons of using ayahuasca as a healing substance.

\section{REFERENCES}

Bogenschutz, M. P., \& Johnson, M. W. (2016). Classic hallucinogens in the treatment of addictions. Progress in Neuropsychopharmacology and Biological Psychiatry, 64, 250-258. https://doi.org/10.1016/j.pnpbp.2015.03.002.

Carbonaro, T. M., Bradstreet, M. P., Barrett, F. S., MacLean, K. A., Jesse, R., Johnson, M. W., et al. (2016). Survey study of challenging experiences after ingesting psilocybin mushrooms: Acute and enduring positive and negative consequences. Journal of Psychopharmacology, 30(12), 1268-1278. https://doi.org/ 10.1177/0269881116662634.

Carhart-Harris, R. L., Bolstridge, M., Rucker, J., Day, C. M. J., Erritzoe, D., Kaelen, M., et al. (2016). Psilocybin with 
psychological support for treatment-resistant depression: An open-label feasibility study. The Lancet Psychiatry, 3(7), 619627. https://doi.org/10.1016/S2215-0366(16)30065-7.

Christiansen, B. A., Smith, G. T., Roehling, P. V., \& Goldman, M. S. (1989). Using alcohol expectancies to predict adolescent drinking behavior after one year. Journal of Consulting and Clinical Psychology, 57, 93-99. http://dx.doi.org/10.1037/0022-006X.57.1.93.

Domínguez-Clavé, E., Soler, J., Elices, M., Pascual, J. C., Álvarez, E., de la Fuente Revenga, M., et al. (2016). Ayahuasca: Pharmacology, neuroscience, and therapeutic potential. Brain Research Bulletin, 126(1), 89-101. https://doi.org/10.1016/j.brainresbull. 2016.03.002.

Frecska, E., Bokor, P., \& Winkelman, M. (2016). The therapeutic potentials of ayahuasca: Possible effects against various diseases of civilization. Frontiers in Pharmacology, 7, 35. https://doi.org/ 10.3389/fphar.2016.00035.

Gaher, R. M., \& Simons, J. S. (2007). Evaluations and expectancies of alcohol and marijuana problems among college students. Psychology of Addictive Behaviors, 21(4), 545. https://doi.org/10. 1037/0893-164X.21.4.545.

Glennon, R. A., Titeler, M., \& McKenney, J. D. (1984). Evidence for 5-HT2 involvement in the mechanism of action of hallucinogenic agents. Life Sciences, 35(25), 2505-2511. https://doi.org/ 10.1016/0024-3205(84)90436-3.

Goldman, M. S., Brown, S. A., \& Christiansen, B. A. (1987). Expectancy theory-thinking and drinking. In K. E. Leonard, \& H. T. Blane (Eds.), Psychological theories of drinking and alcohol (181-226). New York: The Guilford Press.

Griffiths, R. R., Hurwitz, E. S., Davis, A. K., Johnson, M. W., \& Jesse, R. (2019). Survey of subjective "God encounter experiences": Comparisons among naturally occurring experiences and those occasioned by the classic psychedelics psilocybin, LSD, ayahuasca, or DMT. PLoS One, 14(4), e0214377. https:// doi.org/10.1371/journal.pone.0214377.

Grinspoon, L., \& Bakalar, J. B. (1983). Psychedelic reflections. New York: Human Sciences Press.

Grunwell, J. N. (1998). Ayahuasca tourism in South America. Written for Anthropology of Tourism, 8(3), 59-62. Found on MAPS Website: maps-fourm@maps.org.

Hamill, J., Hallak, J., Dursun, S. M., \& Baker, G. (2018). Ayahuasca: Psychological and physiologic effects, pharmacology, and potential uses in addiction and mental illness. Current Neuropharmacology, 16(2), 108-182. https://doi.org/10.2174/ 1570159X16666180125095902.

Harris, R., \& Gurel, L. (2012). A study of ayahuasca use in North America. Journal of Psychoactive Drugs, 44(3), 209-215. https:// doi.org/10.1080/02791072.2012.703100.

Hayaki, J., Hagerty, C. E., Herman, D. S., de Dios, M. A., Anderson, B. J., \& Stein, M. D. (2010). Expectancies and marijuana use frequency and severity among young females. Addictive Behaviors, 35, 995-1000. https://doi.org/10.1016/j.addbeh.2010.06.017.

Jacobs, B. L. (1987). How hallucinogen drugs work: Hallucinogen drugs appear to exert their effects by acting on a specific type of serotonin receptor in the brain. American Scientist, 75(4), 386392.

Jones, B. T., Corbin, W., \& Fromme, K. (2001). A review of expectancy theory and alcohol consumption. Addiction, 96, 5772. https://doi.org/10.1080/09652140020016969.
Kavenská, V., \& Simonová, H. (2015). Ayahuasca tourism: Participants in shamanic rituals and their personality styles, motivation, benefits and risks. Journal of Psychoactive Drugs, 47(5), 351-359. https://doi.org/10.1080/02791072.2015. 1094590.

Kjellgren, A., Eriksson, A., \& Norlander, T. (2009). Experiences of encounters with ayahuasca - "The vine of the soul". Journal of Psychoactive Drugs, 41(4), 309-315. https://doi.org/10.1080/ 02791072.2009.10399767.

Krebs, T. S., \& Johansen, P. O. (2013). Over 30 million psychedelic users in the United States. F1000Research, 2, 98. https://doi.org/ 10.12688/f1000research.2-98.v1.

Labate, B. C., \& Cavnar, C. (Eds.). (2014). Ayahuasca shamanism in the Amazon and beyond. New York: Oxford University Press.

Lawn, W., Hallak, J. E., Crippa, J. A., dos Santos, R., Porffy, L., Barratt, M. J., et al. (2017). Well-being, problematic alcohol consumption and acute subjective drug effects in past-year ayahuasca users: A large, international, self-selecting online survey. Scientific Reports, 7(1), 14700-14706. https://doi.org/10. 1038/s41598-017-14700-6.

Leary, T., Litwin, G. H., \& Metzner, R. (1963). Reactions to psilocybin administered in a supportive environment. Journal of Nervous and Mental Disease, 137, 561-573.

Loizaga-Velder, A. (2013). A psychotherapeutic view on therapeutic effects of ritual ayahuasca use in the treatment of addiction. MAPS Bulletin, 23(1), 36-40.

Loizaga-Velder, A. \& Pazzi, A. L. (2014). Therapist and patient perspectives on ayahuasca- assisted treatment for substance dependence. In B. C. Labate, \& C. Cavanar (Eds.), The therapeutic use of ayahuasca (133-152). Springer.

Luna, L. E. (1986). Vegetalismo: Shamanism among the mestizo population of the Peruvian Amazon. Stockholm: University of Stockholm.

Luna, L. E. (2011). Indigenous and mestizo use of ayahuasca. An overview. In R. G. dos Santos (Ed.), The ethnopharmacology of ayahuasca (1-21). Kerala, India: Transworld Research Network.

McKenna, D. J. (2004). Clinical investigations of the therapeutic potential of ayahuasca: Rationale and regulatory challenges. Pharmacology \& Therapeutics, 102, 111-129. https://doi.org/10. 1016/j.pharmthera.2004.03.002.

McKenna, D. J., Towers, G. H., \& Abbott, F. (1984). Monoamine oxidase inhibitors in South American hallucinogenic plants: Tryptamine and beta-carboline constituents of ayahuasca. Journal of Ethnopharmacology, 10(2), 195-223. https://doi.org/ 10.1016/0378-841(84)90003-5.

McPherson, A., \& Harris, L. M. (2015). Mindfulness, explicit and implicit expectancies in alcohol dependent and non-alcohol dependent adults. International Journal of Mental Health and Addiction, 13(4), 457-469. https://doi.org/10.1007/s11469-0149538-6.

Meng, X. L., Rosenthal, R., \& Rubin, D. B. (1992). Comparing correlated correlation coefficients. Psychological Bulletin, 111(1), 172-175. https://doi.org/10.1037/0033-2909.111.1.172.

Metrik, J., Rohsenow, D. J., Monti, P. M., McGeary, J., Cook, T. A. R., \& de Wit, H., et al. (2009). Effectiveness of a marijuana expectancy manipulation: Piloting the balanced-placebo design 
for marijuana. Experimental and Clinical Psychopharmacology, 17(4), 217-225. https://doi.org/10.1037/a0016502.

Metzner, R. (1999). Ayahuasca: Human consciousness and the spirits of nature. New York: Thunder's Mouth Press.

Metzner, R., Litwin, G. H., \& Weil, G. M. (1965). The relation of expectation and mood to psilocybin reactions: A questionnaire study. Psychedelic Review, 5, 3-39.

Mithoefer, M. C., Mithoefer, A. T., Feduccia, A. A., Jerome, L., Wagner, M., Wymer, J., et al. (2018). 3,4-Methylenedioxymethamphetamine (MDMA) - assisted psychotherapy for post-traumatic stress disorder in military veterans, firefighters, and police officers: A randomized, double-blind, dose-response, phase 2 clinical trial. The Lancet Psychiatry, 5(6), 486-497. https://doi.org/10.1016/S2215-0366(18)30135-4.

Morgan, C., McAndrew, A., Stevens, T., Nutt, D., \& Lawn, W. (2017). Tripping up addiction: The use of psychedelic drugs in the treatment of problematic drug and alcohol use. Current Opinion in Behavioral Sciences, 13, 71-76. https://doi.org/10. 1016/j.cobeha.2016.10.009.

Osório, F. L., Sanches, R. F., Macedo, L. R., dos Santos, R. G., Maiade-Oliveira, J. P., Wichert-Ana, L., et al. (2015). Antidepressant effects of a single dose of ayahuasca in patients with recurrent depression: A preliminary report. Brazilian Journal of Psychiatry, 37(1), 13-20. https://dx.doi.org/10.1590/1516-4446-20141496.

Ot’alora, G. M., Grigsby, J., Poulter, B., Van Derveer, J. W., Giron, S. G., Jerome, L., et al. (2018). 3,4-Methylenedioxymethamphetamine-assisted psychotherapy for treatment of chronic posttraumatic stress disorder: A randomized phase 2 controlled trial. Journal of Psychopharmacology, 32(12), 1295-1307. https://doi. org/10.1177/0269881118806297.

Palhano-Fontes, F., Barreto, D., Onias, H., Andrade, K. C., Novaes, M. M., Pessoa, J. A., et al. (2019). Rapid antidepressant effects of the psychedelic ayahuasca in treatment-resistant depression: A randomized placebo-controlled trial. Psychological Medicine, 49(4), 655-663. https://doi.org/10.1017/ S0033291718001356.

Riba, J., Rodriguez-Fornells, A., Urbano, G., Morte, A., Antonijoan, R., Montero, M., et al. (2001). Subjective effects and tolerability of the South American psychoactive beverage ayahuasca in healthy volunteers. Psychopharmacology, 154, 85-95. https:// doi.org/10.1007/s002130000606.

Riba, J., Valle, M., Urbano, G., Yritia, M., Morte, A., \& Barbanoj, M. J. (2003). Human pharmacology of ayahuasca: Subjective and cardiovascular effects, monoamine metabolite excretion, and pharmacokinetics. Journal of Pharmacology and Experimental Therapeutics, 306(1), 73-83. https://doi.org/10.1124/jpet.103.049882.

Ross, S., Bossis, A., Guss, J., Agin-Liebes, G., Malone, T., Cohen, B., et al. (2016). Rapid and sustained symptom reduction following psilocybin treatment for anxiety and depression in patients with life-threatening cancer: A randomized controlled trial. Journal of Psychopharmacology, 30(12), 1165-1180. https://doi.org/10. 1177/0269881116675512.

Rucker, J. H., Jelen, L. A., Flynn, S., Frowde, K. D., \& Young, A. H. (2016). Psychedelics in the treatment of unipolar mood disorders: A systematic review. Journal of Psychopharmacology, 30(12), 1220-1229. https://doi.org/10.1177/ 0269881116679368 .
Sanches, R. F., de Lima Osório, F., dos Santos, R. G., Macedo, L., Maia-de-Oliveira, J. P., Wichert-Ana, L., et al. (2016). Antidepressant effects of a single dose of ayahuasca in patients with recurrent depression: A SPECT study. Journal of Clinical Psychopharmacology, 36(1), 77-81. https://doi.org/10.1097/JCP.0000000000000436.

dos Santos, R. G. (2013). Safety and side effects of ayahuasca in humans-An overview focusing on developmental toxicology. Journal of Psychoactive Drugs, 45(1), 68-78. https://doi.org/10. 1080/02791072.2013.763564.

dos Santos, R. G., Balthazar, F. M., Bouso, J. C., \& Hallak, E. C. (2016). The current state of research on ayahuasca: A systematic review of human studies assessing psychiatric symptoms, neuropsychological functioning, and neuroimaging. Journal of Psychopharmacology, 30(12), 1230-1247. https://doi.org/10. 1177/0269881116652578.

dos Santos, R. G., Bouso, J. C., Alcázar-Córcoles, M. A., \& Hallak, J. E. C. (2018). Efficacy, tolerability, and safety of serotonergic psychedelics for the management of mood, anxiety, and substance-use disorders: A systematic review of systematic reviews. Expert Review of Clinical Pharmacology, 9, 888-902. https://doi. org/10.1080/17512433.2018.1511424.

Schafer, J. \& Brown, S. A. (1991). Marijuana and cocaine effect expectancies and drug use patterns. Journal of Consulting and Clinical Psychology, 59(4), 558-565.

Schmid, J. T. (2012). The myth of ayahuasca. The International Journal of Religion and Spirituality in Society, 3, 257.

Shalit, N., Rehm, J., \& Lev-Ran, S. (2019). Epidemiology of hallucinogen use in the U.S. results from the national epidemiologic survey of alcohol and related conditions III. Addictive Behaviors, 89, 35-43. https://doi.org/10.1016/j.addbeh. 2018.09.020.

Shanon, B. (Ed.). (2002). The antipodes of the mind: Charting the phenomenology of the ayahuasca experience. New York: Oxford University Press.

Studerus, E., Gamma, A., Kometer, M., \& Vollenweider, F. X. (2012). Prediction of psilocybin response in healthy volunteers. PloS One, 7(2), e30800. https://doi.org/10.1371/journal.pone.0030800.

Swanson, L. R. (2018). Unifying theories of psychedelic drug effects. Frontiers in Pharmacology, 9, 172. https://doi.org/10.3389/fphar. 2018.00172.

Thomas, G., Lucas, P., Capler, N. R., Tupper, K. W., \& Martin, G. (2013). Ayahuasca-assisted therapy for addiction: Results from a preliminary observational study in Canada. Current Drug Abuse Reviews, 6(1), 30-42. https://doi.org/10.2174/ 15733998113099990003.

Tupper, K. W. (2008). The globalization of ayahuasca: Harm reduction or benefit maximization?. International Journal of Drug Policy, 19(4), 297-303. https://doi.org/10.1016/j.drugpo.2006.11.001.

Uthaug, M. V., van Oosouw, K., Kuypers, K. P. C., van Boxtel, M., Broers, N. J., Mason, N. L., et al. (2018). Sub-acute and longterm effects of ayahuasca on affect and cognitive thinking style and their association with ego dissolution. Psychopharmacology (Berlin), 235(10), 2979-2989. https://doi.org/10.1007/s00213018-4988-3.

Wiecko, F. M., Thompson, W. E., \& Parham, B. P. (2017). A high by any other name: Exploring the motivations for consumption of "legal highs". Deviant Behavior, 38(5), 549-560. https://doi. org/10.1080/01639625.2016.1197034. 
Wilcox, R. R. (2013). New statistical procedures for the social sciences: Modern solutions to basic problems. Florence, KY: Psychology Press.

Winkelman, M. (2001). Alternative and traditional medicine approaches for substance abuse programs: A shamanic perspective.
International Journal of Drug Policy, 12, 337-351. https://doi.org/ 10.1016/S0955-3959(01)00100-1.

Winkelman, M. (2011). Drug tourism or spiritual healing? Ayahuasca seekers in Amazonia. Journal of Psychoactive Drugs, 37(2), 209218. https://doi.org/10.1080/02791072.2005.10399803. 